\title{
Seasonal control of odour preferences of meadow voles (Microtus pennsylvanicus) by photoperiod and ovarian hormones
}

\author{
M. H. Ferkin and I. Zucker \\ Department of Psychology, University of California, Berkeley, CA 94720, USA
}

\begin{abstract}
Summary. During the spring-summer breeding season, female meadow voles prefer odours of males over those of females, but in the autumn-winter season of reproductive quiescence this preference is reversed. Females housed in long ( $14 \mathrm{~h} \mathrm{light/day)}$ and short ( $10 \mathrm{~h}$ light/day) photoperiods, respectively, had odour preferences comparable to those of spring and autumn voles, respectively. The preference of long-photoperiod voles for male over female odours was reversed by ovariectomy and restored by treatment with oestradiol. By contrast, neither ovariectomy nor oestradiol affected odour preferences of short-photoperiod voles. Long days appear to influence olfactory preferences by altering ovarian hormone secretion. The failure of oestradiol to affect odour preferences in short photoperiods suggests that the neural substrates mediating this behavioural response are refractory to oestrogens during the nonbreeding season.
\end{abstract}

Ketwords: odour preferences; seasonality; photoperiod; oestradiol; vole

\section{Introduction}

Odour cues signal reproductive status, mark territories and facilitate discrimination among conspecifics (Eisenberg \& Kleiman, 1972; Brown, 1985; Halpin, 1986; Vandenbergh, 1987). Reactions to odours indicate social interactions among microtine rodents (de Jonge, 1980; Reich \& Tamarin, 1980; Stoddart, 1982). Generally, preferential orientation toward a particular odour source reflects nonagonistic or amicable behavioural interactions toward the odour donor (Newman \& Halpin, 1988; Ferkin, 1989; Ferkin \& Rutka, 1990).

In meadow voles, Microtus pennsylvanicus, seasonal differences in odour preferences are most marked among adult females (Ferkin \& Seamon, 1987). Females occupy mutually exclusive territories and intra- and intersexual agonism is high during the spring and summer breeding season (Madison \& McShea, 1987; Ostfeld et al., 1988; Sheridan \& Tamarin, 1988), when a female prefers her own odour and the odour of a male to that of another female (Ferkin \& Seamon, 1987). During the winter nonbreeding season, a female prefers the odours of other females to its own or male odours (Ferkin \& Seamon, 1987). These odour preferences are concomitant with seasonal shifts in social tolerance and are accurate, indirect measures of spacing behaviour.

Seasonally breeding mammals rely on variations in daylength to regulate rhythms in reproduction and social behaviour (Zucker et al., 1980; Bronson \& Perrigo, 1987; Bronson, 1989). Voles housed from birth in long photoperiods (LP) grow more rapidly and reach sexual maturity much younger than those maintained in short photoperiods (SP). Voles born in the spring and autumn share many phenotypic traits with voles housed in LP and SP, respectively (Dark \& Zucker, 1985).

Daylength may affect social behaviour and odour preferences by altering secretion of gonadal hormones or responsiveness of target tissue to gonadal hormones (Morin \& Zucker, 1978; Miernicki et al., 1990). The established relation between gonadal hormones and odour communication in several contexts (Owen et al., 1974; Beatty, 1979; Brown, 1979; Johnston, 1990) suggests that 
natural variations in daylength might affect odour preferences of voles, in part, by altering patterns of gonadal hormone secretion. We assessed the effect of photoperiod and ovarian hormones on odour preferences of female meadow voles. Specifically, we sought to determine whether (i) variations in daylength are sufficient to induce the seasonal differences in odour preference shown in field populations and (ii) ovarian hormones are necessary and sufficient for maintenance of seasonal differences in odour preference.

\section{Materials and Methods}

Animals. Meadow voles, maintained from birth in LP or SP that provided 14 and $10 \mathrm{~h} \mathrm{light} / \mathrm{day}$, respectively (lights on at 07:00 and 09:00 h, respectively), were weaned at 18 days of age and housed with littermates until 35 days of age and singly thereafter in opaque plastic cages $(13 \times 16 \times 3 \mathrm{lcm})$. Wood shavings, cotton nesting material, food (Purina mouse chow *5015, Ralston Purina Co., St Louis, MO, USA) and water were provided ad libitum and room temperature was maintained at $22 \pm 2^{\circ} \mathrm{C}$. Cages were cleaned and the cotton nesting material was replaced weekly. Only odour preferences of females were tested; male voles served as odour donors in the appropriate tests.

Surgical procedure. Females were anaesthetized with a ketamine 'cocktail' $(2.5 \mathrm{mg}$ ketamine hydrochloride, $0.3 \mathrm{mg}$ xylazine and $0.33 \mathrm{mg}$ acetylpromazine all in $0.12 \mathrm{ml}$ ); $0.12 \mathrm{ml}$ of cocktail was injected i.p. per $50 \mathrm{~g} \pm 0.01 \mathrm{ml}$ per each $10-\mathrm{g}$ increase or decrease in body weight. Ovariectomies were performed via a midline incision; the ovarian artery was ligated, the ovary excised and the wound closed with sterile sutures and treated with $0.2 \%$ nitrofurazone (Furacin).

Hormone replacement. Capsules were constructed from Silastic tubing (Dow Corning, Midland, MI, USA; o.d. 0.077 inches, i.d. 0.058 inches $)$, cut into 15 -mm lengths, and filled with crystalline oestradiol- $17 \beta\left(E_{2}\right.$, Sigma Chemical Co., St Louis, MO, USA). The ends of the capsules were plugged with dowels $5 \mathrm{~mm}$ long and sealed with silicon rubber cement, leaving 5-mm lengths of oestrogen-filled tubing. Blank (BL) capsules were prepared similarly, but were left empty. BL and oestradiol capsules were incubated separately in saline for $24 \mathrm{~h}$ before insertion. Capsules were placed subcutaneously in the interscapular area via a small incision that was closed with a wound clip and treated with Furacin. Voles were anaesthetized with methoxyflurane vapours (Metofane: Pitman Moore, Washington, NJ, USA) before implantation of the capsule.

Radioimmunoassay procedure. Upon completion of the final odour preference test, voles from several groups were anaesthetized with Metofane and $0.5-\mathrm{ml}$ aliquots of blood drawn via a capillary tube inserted into the supraorbital capillary bed. The blood was collected in a heparinized vial, centrifuged at 6000 r.p.m. for $15 \mathrm{~min}$, and frozen at

$-20^{\circ} \mathrm{C}$ until the sample was assayed for oestrogen. In plasma oestrogen was assayed using an antiserum that is cospecific for oestradiol- $17 \beta$ and oestrone. Plasma was extracted with ether $(5 \mathrm{ml}: 0.1 \mathrm{ml}$ plasma $)$ and dried extracts were diluted in $50 \mathrm{~mm}$ phosphate-buffered saline $(0 \cdot 1 \mathrm{M}-\mathrm{NaCl})$. Tracer was oestradiol- $\left[2,4,6,7,{ }^{3} \mathrm{H}(\mathrm{N})\right]$ from New England Nuclear (NET-317, $95.4 \mathrm{Ci} / \mathrm{nmol}$ ); bound and free hormone was separated by use of dextran-coated charcoal before radioactivity in supernatants was measured by liquid scintillation. The minimal detectability was $40 \mathrm{pg} / \mathrm{ml}$. The intra-assay coefficient of variation was $10 \%$.

Apparatus. Odour preferences were tested in a covered Plexiglas Y-maze $(149 \times 9 \times 13 \mathrm{~cm})$, which consisted of an acclimation area $15 \mathrm{~cm}$ long at the stem of the $\mathrm{Y}$, a common arm $73 \mathrm{~cm}$ long and 2 choice arms each $76 \mathrm{~cm}$ long. Odourants were placed inside wire baskets in $15-\mathrm{cm}$ chambers at the distal end of each choice arm. These baskets allowed air passage but prevented direct contact of the vole with the cotton. A fan behind the acclimation area pulled air through the Y-maze towards the vole. Air movement measured with a hot-wire anemometer was $0.60 \mathrm{~m} / \mathrm{s}$ through the common arm and $0.30 \mathrm{~m} / \mathrm{s}$ through the choice arms. The apparatus and testing procedure were described in detail by Ferkin $\&$ Seamon (1987).

Procedure. Voles were placed in the acclimation area behind a movable screen door for $1 \mathrm{~min}$ before the door was raised and they were exposed to two air currents from the separate arms of the maze. The odour stimuli in the maze arms were provided by cotton nesting material taken from a cage that housed a single animal for at least the preceding $24 \mathrm{~h}$. Scented cotton was always taken from individuals of similar age to the focal vole. Odour donors and focal (test) voles were unrelated to and unfamiliar with each other. Each of the 2 wire baskets contained cotton impregnated with one of the stimulus odours placed in the right or left position at random. Cotton pieces were of similar size, weighed $8 \pm 2 \mathrm{~g}$ and were not used in more than 2 consecutive trials. The assignment of the stimulus odours was unknown to the observer. Depending on the experiment, each female underwent 3-4 odour preference tests at intervals of 5 days; testing was between 10:00 and 15:00 h. The Y-maze and wire baskets were cleaned with ethanol between trials.

During each 5-min trial the initial odour choice of the vole and the time spent in the choice arms were recorded to the nearest second. Wilcoxon matched-pairs signed-ranks tests assessed the significance between the paired sets of observations (two-tailed, alpha $=0.05$ ). Voles in a given treatment condition were considered to show an odour preference if they spent significantly more time in the maze arm containing a specific odour. 


\section{Experiment 1}

Nulliparous females ( $n=16$ /group), born and reared in SP or LP, were given odour preference tests in which they chose between cotton bedding from an LP or SP female vs. that from an LP or SP male, bedding from SP vs. LP females, SP vs. LP males, bedding from a female of the same photoperiodic history vs. that from the focal vole's cage (self), or bedding from a male of the same photoperiodic history vs. that of unsoiled (fresh) cotton. Testing was initiated when voles were 50-60 days old and completed when they were $\sim 90$ days old.

\section{Experiment 2}

Females ( $n=16$ /group) were ovariectomized (OVX) between 35 and 45 days of age and given odour preference trials 25-29 days later. The testing procedure was identical to that of Exp. 1. SP-OVX females chose from among the following odour pairings: SP female vs. LP female, LP male vs. SP male, LP female vs. LP male, or their own vs. SP female odour. The tests for LP-OVX females included SP female vs. LP female, SP male vs. LP male, SP male vs. SP female, or their own vs. LP female odour.

\section{Experiment 3}

SP and LP females were OVX between 35 and 45 days of age, implanted with a blank capsule (BL) 10 days later, and tested for odour preferences 15 days after receiving the implant. SP-OVX-BL voles were tested with SP female vs. SP male, their own odour vs. SP female, SP female vs. LP female, and LP male vs. SP male odour. LP-OVX-BL females were tested with odours from LP male vs. LP female, LP female vs. their own odour, LP female vs. SP female, and LP male vs. SP male odour.

After these tests, BL capsules were removed and replaced with capsules containing oestradiol-17 7 , when voles were $\sim 90$ days old; $25-29$ days later, these voles (SP-OVX-E ${ }_{2}$ and LP-OVX-E $_{2}$ ) underwent the same odour preference tests as SP-OVX-BL and LP-OVX-BL animals, respectively. Sample size was $16 /$ group. Blood was drawn from 12 of the hormone-treated females in each photoperiod within 3-5 days of their final odour preference test and assayed for plasma concentrations of $E_{2}$. The interval between capsule implantation and $E_{2}$ determinations ranged from 49 to 52 days.

A within-study replication was performed. An additional 32 female voles born and reared in SP $(n=16)$ and LP $(n=16)$, respectively, were $\mathrm{OVX}$ between 35 and 40 days of age, implanted with $\mathrm{E}_{2}$ capsules between 70 and 80 days of age, and 15 days later tested for odour preferences.

\section{Results}

Autopsy of a random sample of male odour donors indicated that SP males had regressed testes (paired testes weights of $0.34 \pm 0.07 \mathrm{~g}, \bar{X} \pm$ s.e.; $n=5$ ) and LP males had developed testes $(1.33 \pm 0.03 \mathrm{~g}, n=5 ; t=9.79,8 d . f ., P<0.001)$. Initial choice of an odour of ten coincided with the eventually preferred odour across all tests in $\operatorname{SP}\left(\chi^{2}=5.42,1 d . f ., P<0.05\right)$ and $\operatorname{LP}\left(\chi^{2}=8.96\right.$, $1 d . f ., P<0.05)$.

\section{Experiment 1}

Female meadow voles did not display a left- or right-side bias in their odour choices $\left(\chi^{2}=1 \cdot 07\right.$, $P>0.05$ ). LP females preferred odours of LP males over those of LP females ( $\mathrm{lm}>$ If; Fig. 1a) and LP female over fresh cotton odours (lf $>$ c; Fig. 1a), but did not show a preference between the odours of other LP females and their own odour (lf vs. s; Fig. la). SP females preferred SP female over SP male odours (sf > sm; Fig. 1b), SP female over their own odours (sf > s; Fig. 1b), and SP female over fresh cotton odours (sf $>$ c; Fig. 1b). LP females preferred odours of LP males to those of SP males ( $\mathrm{lm}>\mathrm{sm}$; Fig. 2a), but did not display a preference between SP female and LP female (sf vs. If; Fig. 2a) or SP male and SP female odours (sm vs. sf; Fig. 2a). SP females preferred SP female to LP female odours (sf > If; Fig. 2b), but did not display a preference between SP male and LP male (sm vs. lm; Fig. 2b) or LP female and LP male odours (lf vs. lm; Fig. 2b). 


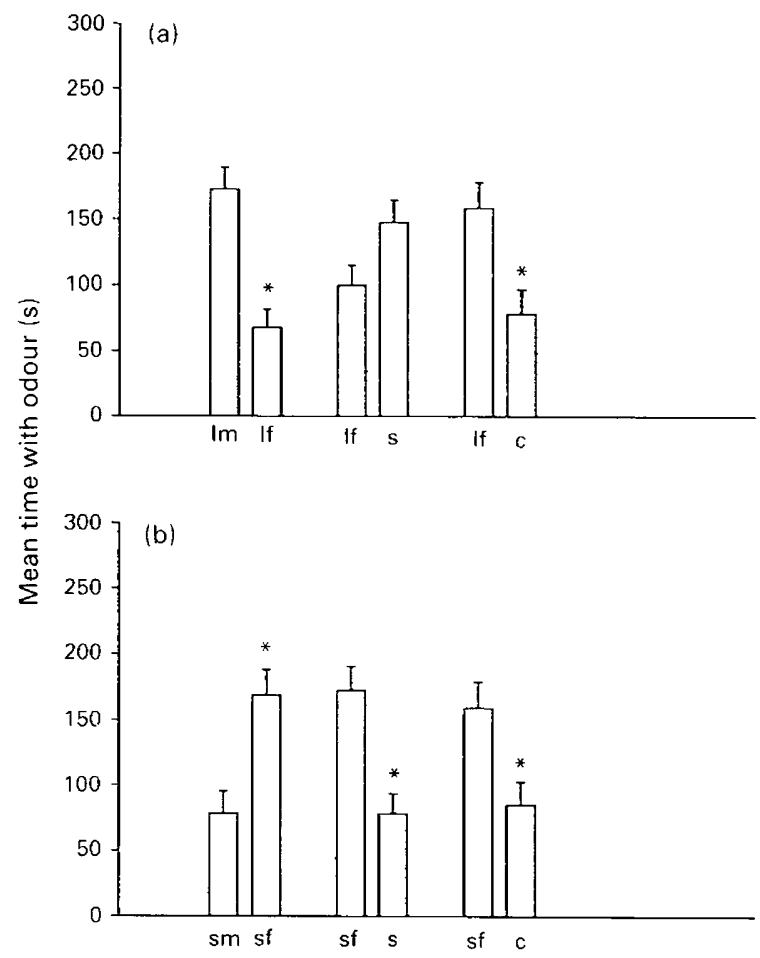

Fig. 1. Mean time ( \pm s.e.) that (a) long-photoperiod (LP) female voles spent with $1 m$ (LP male) vs. If (LP female) odour, If vs. s (self) odour, and if vs. c (fresh cotton), and (b) short-photoperiod (SP) females spent with sm (SP male) vs. sf (SP female) odour, sf vs. s, and sf vs. c odours. $n=16$ focal voles for each paired comparison; * indicates significant difference between odour pairs, Wilcoxon matched-pairs signed-ranks test at $P<0.05$ in this and subsequent figures.

\section{Experiment 2}

LP-OVX females preferred the odours of LP females over those of LP males (1f $>1 \mathrm{~m}$; Fig. 3a), but did not display a preference in each of the following odour-pair tests: their own odour vs. that of other LP females (s vs. If), SP female vs. LP female (sf vs. If), or LP male vs. SP male odours (lm vs. sm; Fig. 3a).

SP-OVX females preferred the odours of SP females to those of SP males ( $\mathrm{sf}>\mathrm{sm}$ ), odours of SP females over their own odours ( $f f>s$ ) and SP female over LP female odours (sf $>$ lf; Fig. 3b), but did not display a preference between SP male and LP male odours (sm vs. Im; Fig. 3b).

\section{Experiment 3}

LP-OVX-BL females preferred the odours of LP females to those of LP males (If $>\operatorname{lm}$; Fig. 4a), but did not display a preference between those of other LP females and their own odours (lf vs. s), LP female vs. SP female (If vs. sf), or LP male vs. SP male odours (lm vs. sm; Fig. 4a). The odour preference profiles of LP-OVX-BL, LP-OVX, and intact SP females were similar. SP-OVX-BL females preferred SP female over SP male and LP female odours (sf > sm; sf $>$ If), but did not display preferences between their own odour or SP female (s vs. sf), or LP male and SP male odours (lm vs. sm; Fig. 4b).

LP-OVX-E ${ }_{2}$ females preferred LP male over LP female odours ( $\mathrm{lm}>$ If; Fig. 5a), their own odours over LP female odours (s > If; Fig. 5a) and LP male over SP male odours ( $\mathrm{lm}>$ sm; Fig. 


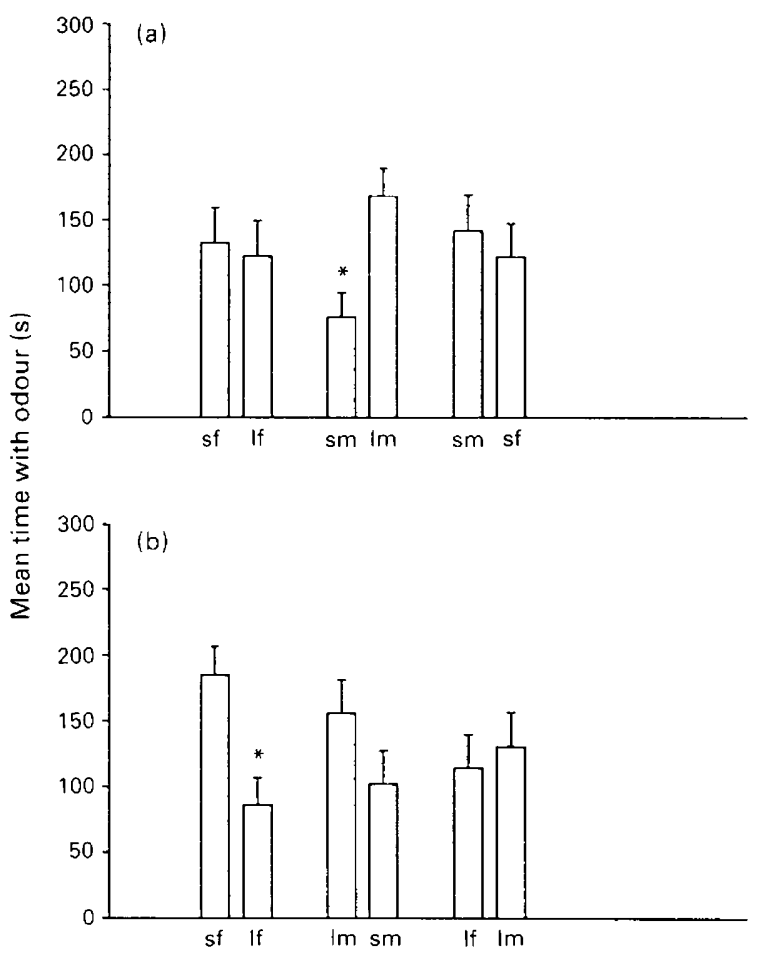

Fig. 2. Mean time that (a) long-photoperiod female voles spent with sf vs. If, sm vs. $1 \mathrm{~m}$, and sm vs. sf odours; and (b) short-photoperiod females spent with sf vs. If, $1 \mathrm{~m}$ vs. sm, and If vs. Im odours. Abbreviations as in Fig. 1.

5a), but did not display a preference between LP female and SP female odours (lf vs. sf; Fig. 5a). SP-OVX-E ${ }_{2}$ females preferred the odours of SP females to those of SP males (sf > sm; Fig. 5b) and SP female to LP female odours (sf $>$ If; Fig. 5b), but did not display a preference in the following odour-pair tests: their own odour vs. those of SP females (s vs. sf; Fig. 5b) and LP male vs. SP male odours (lm vs. sm; Fig. 5b).

Oestradiol values were available for $12 \mathrm{LP}-\mathrm{OVX}-\mathrm{E}_{2}$ and $10 \mathrm{SP}-\mathrm{OVX}-\mathrm{E}_{2}$ females. The groups did not differ significantly (LP, $759 \pm 118$ vs. SP, $990 \pm 484 \mathrm{pg} / \mathrm{ml} ; t=0 \cdot 50,20$ d.f., $P>0.6$ ). The high variability in the latter group was attributable to one unusually high value $(5315 \mathrm{pg} / \mathrm{ml})$. When this value was deleted, the oestradiol concentration for this group decreased to $509 \pm 62 \mathrm{pg} / \mathrm{ml}$, but the LP and SP groups still did not differ significantly $(t=1 \cdot 70,19$ d.f., $P>0 \cdot 1)$.

In the replication, virtually no significant differences were detected between odour preferences of SP females treated with $E_{2}$ and those treated with $E_{2}$ after treatment with BL capsules. In comparing the original and replication experiments, only one result differed significantly: in the replication SP-OVX-E $E_{2}$ females preferred SP female over LP female odours; this difference was only marginally significant $(P<0.06)$ in the original study.

\section{Discussion}

Seasonal variation in daylength appears to be the principal factor responsible for changes in odour preferences of female meadow voles. Females housed in a long photoperiod preferred male to female odour, their own odour to that of another female, and the odour of a long-day male to that of a short-day male. In contrast, females kept in a short photoperiod preferred female to male odour, the odour of another female to their own odour, and short-day female odour over long-day 


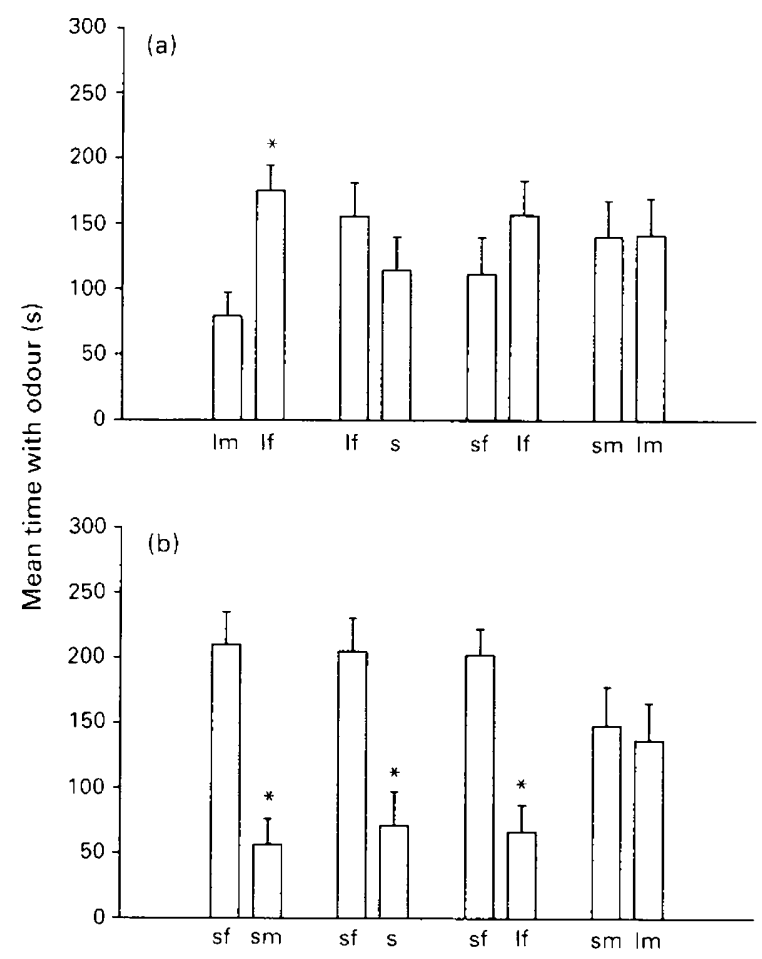

Fig. 3. Mean time that (a) long-photoperiod ovariectomized female voles spent with $1 \mathrm{~m}$ vs. If, If vs. s, sf vs. If, and sm vs. Im odours; and (b) short-photoperiod ovariectomized females spent with sf vs. sm, sf vs. s, sf vs. If, and sm vs. Im odours. Abbreviations as in Fig. 1.

female odour. Thus, long and short days are sufficient to induce odour preferences in female voles similar to those of free-living females during the spring breeding season and the autumn season of reproductive quiescence, respectively (Ferkin \& Seamon, 1987). Beach voles, $M$. breweri also prefer odours of opposite-sex to same sex conspecifics during the breeding season, but not during times of reproductive arrest (Reich \& Tamarin, 1980; Ferkin, 1990). Variation in daylength is the most accurate indicator of geophysical phase available to voles and other seasonal breeders (Christian, 1980; Bronson \& Perrigo, 1987; Nelson, 1987; Bronson, 1989) and seems to mediate seasonal shifts in odour preference.

Seasonal differences in odour preferences are contemporaneous with shifts in spacing, female territorial behaviour and social tolerance (Madison \& McShea, 1987; Ostfeld et al., 1988; Sheridan \& Tamarin, 1988). In late autumn, breeding ceases and social tolerance increases among conspecifics (Madison et al., 1984; McShea, 1990). Short days may signal communal nesting, reduced aggression between females, relaxation of female territorial boundaries and sharing of resources. The odour preferences of short-photoperiod females and free-living females in autumn are consistent with this view. In spring, adults are breeding and social intolerance characterizes behavioural interactions among conspecifics (Madison \& McShea, 1987). Long days may control female territoriality, sexual behaviour, increased female-female agonism and individual nesting. Photoperiod also mediates social behaviour and aspects of olfactory communication in Syrian hamsters (Fleming et al., 1988; Badura \& Nunez, 1989; Miernicki et al., 1990).

Ovarian hormones influenced odour preferences of long- but not short-photoperiod voles. The preference of long-photoperiod females for male over female odour was reversed by ovariectomy. Oestrogen replacement in LP-OVX females restored the preference for male over female odour. Odour preferences in long-photoperiod females depend on ovarian hormone secretion, probably 


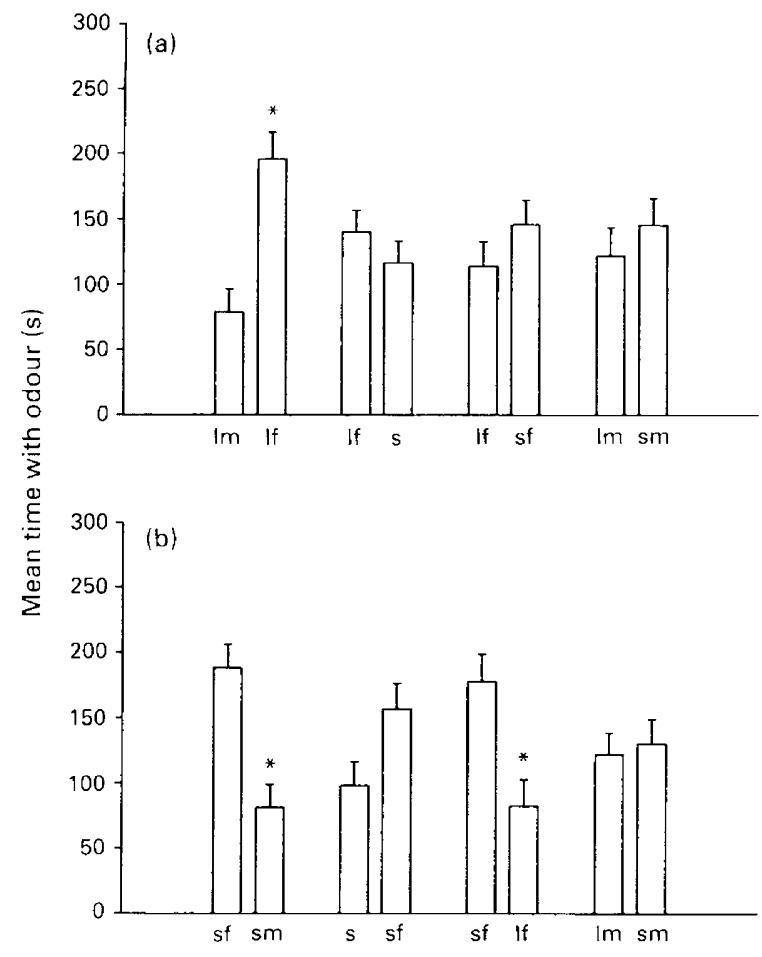

Fig. 4. Mean time that (a) long-photoperiod, ovariectomized female voles implanted with blank capsules spent with $\mathrm{lm}$ vs. If, If vs. s, If vs. sf, and Im vs. sm odours; and (b) short-photoperiod, ovariectomized females implanted with blank capsules spent with sf vs. sm, s vs. sf, sf vs. If, and $1 \mathrm{~m}$ vs. sm odours. Abbreviations as in Fig. 1.

oestradiol. The odour preference profile of LP-OVX voles was more like that of intact shortphotoperiod than of long-photoperiod females. Both intact short-photoperiod and LP-OVX females preferred female to male odour. In contrast, odour preferences of short-photoperiod females are independent of ovarian hormones, as they are affected neither by ovariectomy nor oestradiol treatment. The odour preference profile of SP-OVX voles was similar to that of intact short-photoperiod females. SP-OVX females treated with oestradiol also retained a shortphotoperiod odour preference profile. Thus, odour preferences of short-photoperiod voles, unlike those of long-photoperiod females, are unresponsive to oestradiol.

The failure of oestradiol to influence odour preferences of short-photoperiod voles cannot be attributed to inadequate hormone concentrations, since oestradiol concentrations were similar in short- and long-photoperiod females implanted with oestradiol capsules. The difference may reflect short-day patterns of pituitary or pineal gland hormone secretions. These hormones may alter responsiveness to oestradiol in neural target tissues that mediate olfactory behaviour (Pfaff \& Pfaffmann, 1969; Badura \& Nunez, 1989). Similar results and interpretations have been adduced to account for the failure of ovarian hormones to affect aggressive behaviour in short-day female golden hamsters (Fleming et al., 1988). Short photoperiods also override the effects of ovarian hormones on body weight of female voles (Dark et al., 1984, 1986).

During the winter, reproductively quiescent female voles relax territorial boundaries and form communal nesting aggregations (Madison et al., 1984), coincident with a social preference for, and reduced agonism towards, other females, but not males (Ferkin \& Seamon, 1987; Ferkin, 1988). Presumably, preference for females, coupled with high levels of agonism toward males, would limit a female's contact with males and exposure to the primer pheromones in male urine (Carter $e t$ al., 


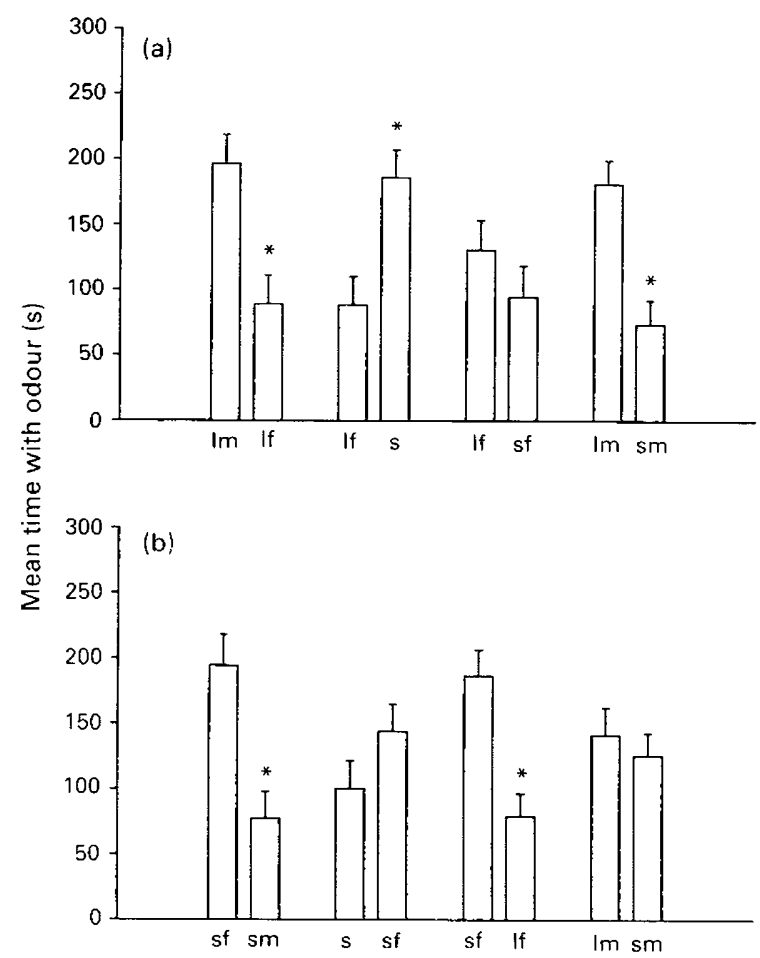

Fig. 5. Mean time that (a) long-photoperiod ovariectomized female voles implanted with oestradiol-filled capsules spent with $\mathrm{Im}$ vs. If, If vs. s, If vs. sf, and Im vs. sm odours; and (b) short-photoperiod, ovariectomized females implanted with $E_{2}$ capsules spent with sf vs. sm, $s$ vs. sf, sf vs. If, and lm vs. sm odours.

1987). This, in turn, may effect a change in neural responsiveness to oestrogen (Cohen-Parsons \& Carter, 1987; Cohen-Parsons \& Roy, 1989).

Familiarity with odour donor, age, genetic relatedness and parity also affect odour preferences and reproduction of voles (Carter et al., 1988; Newman \& Halpin, 1988; Ferkin, 1989). Indeed, in some circumstances familiarity may supersede the effects of photoperiod and ovarian hormones. Under field conditions, variation in daylength probably accounts for a major portion of seasonal variance in olfactory preferences and social behaviour.

We thank M. Gorman, J. Dark and S. Ferkin for comments on earlier drafts of the manuscript, G. Brooks and E. Moore for excellent animal care, S. Pavgi and P. Licht for performing the hormone assays, supported by NSF grant DCB-90-4040576, and K. Pelz for technical assistance. This research was supported by NRSA postdoctoral fellowship 1F32NS08792-01 to M. H. Ferkin and NIH grant HD 02982.

\section{References}

Badura, L.L. \& Nunez, A.A. (1989) Photoperiodic modulation of sexual and aggressive behavior in female golden hamsters (Mesocricetus auratus): role of the pineal gland. Horm. Behav. 23, 27-42.

Beatty, W. (1979) Gonadal hormones and sex differences in nonreproductive behaviors in rodents: organizational and activational influences. Horm. Behav. 12, $112-163$
Bronson, F.H. (1989) Mammalian Reproductive Biology. University of Chicago Press, Chicago.

Bronson, F.H. \& Perrigo, G. (1987) Seasonal regulation of reproduction in muroid rodents. Am. Zool. 27,929-940.

Brown, K. (1979) Chemical communication between animals. In Chemical Influences on Behaviour, pp. 599-649. Eds K. Brown \& S. J. Cooper. Academic Press, New York. 
Brown, R.E. (1985) The rodents. II: Suborder Myomorpha. In Social Odours in Mammals Vol. 1, pp. 345-457. Eds R. E. Brown \& D. W. Macdonald. Oxford University Press, Oxford.

Carter, S.C., Witt, D.M., Schneider, J., Harris, Z.L. \& Volkening, D. (1987) Male stimuli are necessary for female sexual behavior and uterine growth in prairie voles (Microtus ochrogaster). Horm. Behav. 21, 7482

Carter, C.S., Witt, D.M., Thompson, G. \& Carlstead, K. (1988) Effects of hormonal, sexual, and social history on mating and pair bonding in prairie voles. Physiol. Behav. 44, 691697.

Christian, J.J. (1980) Regulation of annual rhythms of reproduction in temperate small rodents. In Testicular Development, Structure, and Function, pp. 367 380. Eds A. Steinberger \& E. Steinberger. Raven, New York.

Cohen-Parsons, M. \& Carter, C.S. (1987) Males increase serum estrogen and estrogen receptor binding in brain of female voles. Physiol. Behav. 39, 309 . 314.

Cohen-Parsons, M. \& Roy, E.J. (1989) Social stimuli augment estrogen receptor binding in preoptic area of female prairie voles. Brain Res. 476, 363-366.

Dark, J. \& Zucker, I. (1985) Seasonal cycles in energy balance: regulation by light. Ann. N.Y. Acad. Sci. 453, 170181 .

Dark, J., Zucker, I. \& Wade, G.N. (1984) Short photoperiods counteract the effects of ovariectomy on energy balance in meadow voles. Am. J. Physiol. 246, R3I-R34.

Dark, J., Zucker, I. \& Wade, G.N. (1986) Short daylengths decrease body mass of overweight female voles. Physiol. Behav. 38, 381-384.

de Jonge, G. (1980) Response to con- and hetero-specific male odours by the voles Microtus agrestis, $M$. arvalis, and Clethrionomys glareolus with respect to competition for space. Behaviour 73, 277-302.

Eisenberg, J.F. \& Kleiman, D.G. (1972) Olfactory communication in mammals. Ann. Rev. Ecol. Syst. 3, $1-32$.

Ferkin, M.H. (1988) Seasonal differences in social bchavior among adult and juvenile meadow voles, Microtus pennsylvanicus. Ethology 79, 116-125.

Ferkin, M.H. (1989) Adult-weanling recognition among captive meadow voles (Microtus pennsylvanicus). Behaviour 118, 114124.

Ferkin, M.H. (1990) Odor selections of island beach voles during their nonbreeding season. J. Mammal. 71,397401 .

Ferkin, M.H. \& Seamon, J.O. (1987) Odor preferences and social behavior in meadow voles, Microtus penns.lvanicus: seasonal differences. Can.J. Zool. 65, 29312937.

Ferkin, M.H. \& Rutka, T.F. (1990) Mechanisms of sibling recognition in meadow voles. Can. J. Zool. 68, $609-613$.

Fleming, A.S., Phillips, A., Rydall, A. \& Levesque, L. (1988) Effects of photoperiod, the pineal gland and the gonads on agonistic behavior in female golden hamsters (Mesocricetus auratus). Physiol. Behav. 44, $227-234$.
Halpin, Z.T. (1986) Individual odors among mammals: origins and functions. Adv. Study Behav. 16, 39-70.

Johnston, R.E. (1990) Chemical communication in golden hamsters: from behavior to molecules and neural mechanisms. In Contemporary Issues in Comparative Psychology, pp. 381-409. Ed. D. A. Dewsbury, Sinauer Press, Sunderland, MA.

Madison, D.M. \& McShea, W.J. (1987) Seasonal changes in reproductive tolerance, spacing, and social organization in meadow voles: a microtine model. Am. Zool. 27, 899-908.

Madison, D.M., Fitzgerald, R.W. \& McShea, W.J. (1984) Dynamics of social nesting in overwintering meadow voles (Microlus pennsylvanicus). Behav. Ecol. Sociobiol. 15, 917.

MeShea, W.J. (1990) Social tolerance and proximate mechanisms of dispersal among winter groups of meadow voles. Microtus pennsylvanicus. Anim. Behav. 39, 346-351.

Miernicki, M., Pospichal, M.W. \& Powers, J.B. (1990) Short photoperiods affect male hamster sociosexual behaviors in the presence and absence of testosterone. Physiol. Behav. 47, 95-106.

Morin, L.P. \& Zucker, I. (1978) Photoperiodic regulation of copulatory behaviour in the hamster. J. Endocrinol. 77, 249-258.

Nelson, R.J. (1987) Photoperiod-nonresponsive morphs: a possible variable in microtine population-density fluctuations. Am. Nat. 130, 350 369 .

Newman, K.S. \& Halpin, Z.T. (1988) Individual odours and mate recognition in the prairie vole. Microtus ochrogaster. Anim. Behav. 36, 1779-1787.

Ostfeld, R.S., Pugh, S.R., Seamon, J.O. \& Tamarin, R.H. (1988) Space use and reproductive success in a population of meadow voles. J. Anim. Ecol. 57, 385-394.

Owen, K., Wallace, P. \& Thiessen, D.D. (1974) Effects of intracerebral implants of steroid hormones on scent marking in the ovariectomized female gerbil, Meriones unguiculatus. Physiol. Behav. 12, 755-760.

Pfaff, D.W. \& Pfaffmann, C. (1969) Behavioral and electrophysiological responses of male rats to female rats urine odors. In Olfaction and Taste $I I$, pp. 258-267. Ed. C. Pfaffmann. Rockefeller University Press, N.Y.

Reich, L.M. \& Tamarin, R.H. (1980) Trap use as an indicator of social behavior in mainland and island voles. Acta Theriol. 23, $295 \cdots 307$.

Sheridan, M. \& Tamarin, R.H. (1988) Space use, longevity, and reproductive success in meadow voles. Behav. Ecol. Sociobiol. 22, 85-90.

Stoddart, D.M. (1982) Demonstration of olfactory discrimination by the short-tailed vole, Microtus agrestis (L.). Anim. Behav. 30, 293-301.

Vandenbergh, J.G. (1987) Regulation of puberty and its consequences on population dynamics of mice. $\mathrm{Am}$. Zool. 27, 891-898.

Zucker, I., Johnston, P.G. \& Frost, D. (1980) Comparative, physiological and biochronometric analyses of rodent seasonal reproductive cycles. Prog. Reprod. Biol. 5, 102-133.

Received 10 September 1990 